\title{
Application of Browser/Server Architecture in College English Online Learning System Design
}

\author{
https://doi.org/10.3991/ijet.v13i03.8395 \\ Lidan Mao( $\left.{ }^{\varpi}\right)$, Jun Miao \\ Agriculture University of Hebei, Baoding, China \\ mia_mao@163.com
}

\begin{abstract}
In order to realize the information management of college English learning, improve the management efficiency of college English teaching, and reform the traditional applied teaching mode, this paper proposed to design a college English online learning system, which uses Browser/Server $(\mathrm{B} / \mathrm{S})$ as the architecture, JSP technology as the programing language, and MySQL database technology as the data storage and management database. Then, this paper fully analyzed the requirements of network English teaching and management and the demands of system users. On this basis, functional module, database design and overall system architecture were designed, with the relevant interface displayed. The design and implementation of the system can improve the efficiency and quality of English teaching and effectively advance the teaching level of college English, which can be applied into extensive fields.
\end{abstract}

Keywords - B/S, JSP, MySQL database, online English learning, system design

\section{Introduction}

Informatization is the general trend of economic development worldwide today, and the degree of informatization in the field of education in our country is also increasing year by year. In order to adapt to the new viewpoint of elementary education reform proposed by the state, more and more scholars in China have paid more attention to the informatization of the educational industry [1] However, in the process of actual English education in Chinese colleges and universities, the traditional teaching mode is still commonly used in English teaching in our country, which deviates from the trend of educational informationization. For English learning that requires a highly active participation of both learners and teachers, the traditional teaching model has no longer meet the increasing demands [2].

E-Learning or online learning, as an indispensable part of the development of modern educational informatization, provides a new communication mechanism and abundant learning resources, enabling a brand-new e-learning environment for teaching [3]. A survey conducted by the Campus Computing Project in the United States in 2015 shows that over $85 \%$ of U.S. campuses have implemented online learning systems in schools, with the penetration rate increasing from $10 \%$ in 2000 to $85 \%$. This 
shows that online learning has good application prospects and effect [4]. Although English learning websites and online learning systems have continuously sprung up in recent years and have enriched teaching resources to a certain extent and provided multi-dimensional learning options, the systems are still deficient in functionality, security, interactivity and openness [5]. Some scholars have established an English learning system based on campus network, but the management function is imperfect, failing to meet the requirements of teaching management. Some scholars have proposed a corpus-based English learning model, but due to the lack of teaching-learning communication, the teaching effectiveness is poor. At present, there are some shortcomings of the existing online English learning system, such as the imperfect teaching mechanism, homogeneous contents, the lack of innovation, and the insufficient network security [6]

This paper aims to provide a highly interactive, intelligent, safe, and cultural online English learning platform. The system take B / S as the software development architecture, and MySQL as the database development tools, combined with JSP dynamic web development technology, to achieve re-development and operations in most computer hardware. At the same time, the system uses object-oriented approach to meet the actual English learning needs and teaching management needs. This paper analyzed the system design goals and main functional requirements in details, completed the system design and interface design, and finally realized the design of the online English learning system based on the B / S framework. The implementation of the system can improve the quality of teaching and learning, meet the needs of the teaching data, software platform, hardware equipment, and network equipment, and provide a information platform for communication, learning, and interaction among students, teachers and administrators.

\section{Introduction to Relevant Computer Technologies}

\subsection{B / S Mode}

B / S structure (Browser / Server mode) is an effective improvement of the C / S structure with the development of Internet technology, which is realized in the user interface through the browser. And the vast majority of logical transactions are achieved in the server. This reduces the load on the client computers and increases the efficiency of system maintenance and upgrades [7]. The data access in the B / S mode starts from the presentation layer to the application layer and then to the data layer, so the system architecture of the $\mathrm{B} / \mathrm{S}$ mode is also divided into the presentation layer, application layer, and data layer, as shown in Figure 1. 


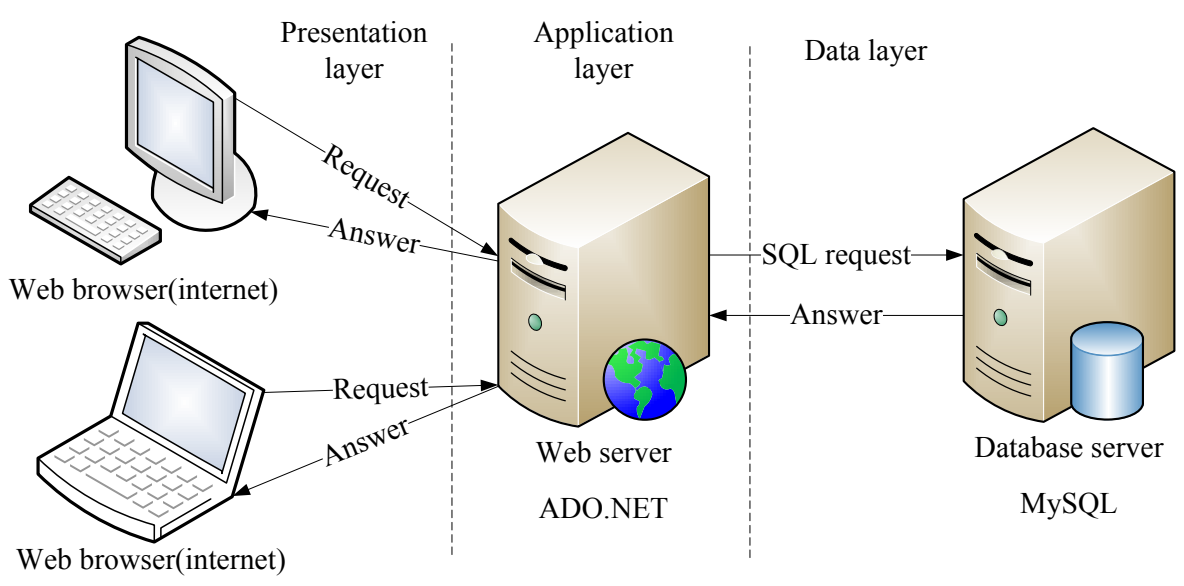

Fig. 1. B/S System architecture diagram

B / S architecture software has the advantages of simple maintenance and upgrades, and main maintenance is on the server, greatly improving the maintenance efficiency. The B / S architecture is suitable for Linux operating system, Window operating system, and a variety of free databases, reducing system operating costs [8].

Compared with the C / S mode, the B / S mode can be built on the WAN and doesn't necessarily require a special network hardware environment, with a stronger adaptability. The $\mathrm{C} / \mathrm{S}$ mode interacts through the browser. The common browser can be found in each client machine, leading to relatively low safety. Therefore, the model is suitable for high interactive requirements and more users but low safety requirements. The B / S mode requires that relatively independent components and can be reused. In summary, the $\mathrm{C} / \mathrm{S}$ development model and $\mathrm{B} / \mathrm{S}$ development model both belong to the development model under network environment, and the $\mathrm{B} / \mathrm{S}$ model has relatively more advantages through analysis, so now a large number of applications gradually shift from $\mathrm{C} / \mathrm{S}$ mode to $\mathrm{B} / \mathrm{S}$ mode.

In summary, the system used the B / S architecture, which is more suitable for the current network development environment and has more advantages in convenience, security, etc.

\subsection{JSP Programing Language}

JSP, namely Java Server Pages, is a dynamic web technology standard. JSP can be obtained through simply developing WEB program. With a simple HTML foundation, by modifying the script file, htm file can be transferred into .jsp file. Using JSP development technology, the web server receives the request to access the JSP page, executes the program segment, and returns the result together with the HTML code to the client [9].

The applications of the JSP technology under the B / S mode has the following characteristics: 
1. JSP development language is easy to write, which one can quickly master based on HTML and Java language, and only addition of JSP fields in the HTML pages written by web author, can realize JSP pages.

2. Just one programing can realize multiple operations. Edit all JSPs into Java servlets , then it will have all the benefits of Java technology [10].

3. With high reusability, JSP, when re-called, only requires changes in the internal design, without changing the code to improve the system reusability.

4. JSP is cross-platform, which is in line with the B / S model. JSP can run on almost all operating system platforms, and can be ported on different platforms.

5. It can be connected with most database technologies, including Mircosoft Server, Oracle, Sybase, MySQL, Informix, etc. also, it can realize connection between drivers and database on basis of JDBC (Java Database Connectivity).

\subsection{Introduction to MySQL}

MySQL is a popular open source SQL data management system. The MySQL service supports the use of heavy-duty production systems, or it can be embedded in software with large configuration [11].

MySQL features include the following points: 1. It is programmed by $\mathrm{C}$ and $\mathrm{C}++$, and can be tested by multiple compilers to ensure code portability. 2. It supports AIX, FreeBSD, Linux, Mac OS, Windows, and other operating systems. 3. It provides APIs for multiple programming languages. 4. It optimizes the SQL query algorithm. 5. It optimizes the SQL query algorithm, speeding up the database query and access. 6. It provides multiple database connectivity options such as TCP / IP, ODBC, and JDBC [12].

Although MySQL is not as large as Oracle, DB2, SQL Server and other large databases, its access speed is objective, without open source software code and lower cost, making it the best choices for college students' online English learning system database [13].

\section{$3 \quad$ Analysis of Requirements for Online English Learning System}

\subsection{Analysis of English Teaching and Management Needs}

System operation process is that firstly teachers and administrators enter learning tasks, comprehensive testing and other learning content into system. Students complete the relevant learning content after registering in the system, and exchange difficult learning points and learning experience through online communication with teachers. Teachers monitor the effectiveness of student learning and inquiries through the system to get the real-time situation of students learning and tests. Administrators manage teachers and their classes [14].

English online learning system includes management of administrator activities, teacher activity management, student learning, testing and communication activities 
management and other basic functions of management. The traditional English learning system can not break through the limitation of time and place, and the corresponding management requires teachers to spend a lot of manpower and time to correct the homework, and can not understand the process of students' learning in real time or learn the problem in students' learning in time. In order to improve the efficiency of English learning and teaching management, colleges and universities need a more intelligent and efficient English online learning system [15].

\subsection{Users' Functional Requirements for Online Learning System}

System Administrator. Administrators can query, add, modify or delete teacher information, assign the class to the appropriate teacher, and change or delete classes for teachers. Administrators can access to the background management module to maintain personal information and manage teachers' classes.

System requirements for the administrator module include adding teachers, deleting teachers, modifying teacher information, querying teacher information, adding classes, deleting classes, modifying class information, and querying class information.

Teachers. Teachers need to $\log$ in the system, maintain personal information, and visit and operate teacher functional module. Also, teachers need to query and manage information such as students' learning progress, study notes and dictionary contents in the system, and design students' comprehensive tests and writing tests. After students complete relevant tests, they can inquire the students' academic performance in order to master the students' present level of learning. At the same time, teachers need to regularly reply to forum-related posts and answer questions raised by students in the learning process.

The system requirements for the teacher function module include teacher information modification, student information review, test grade review, study assignment placement, learning progress review, posting, replying, etc. [16].

Students. Students need to log in the system, maintain personal information, visit the learning task test interface, check the learning progress, study notes and vocabulary dictionary on the learning task interface, complete the comprehensive test and writing test in the test page, review their own comprehensive score and writing test performance after completing, and post Q\&A in the forum module. The students' case is shown in Figure 2.

\subsection{System Function Requirements}

System functional requirements refer to all functions that the software system should have. Through analyzing the English online learning management needs and user needs, the main functions of the system are obtained as shown in Table 1. 


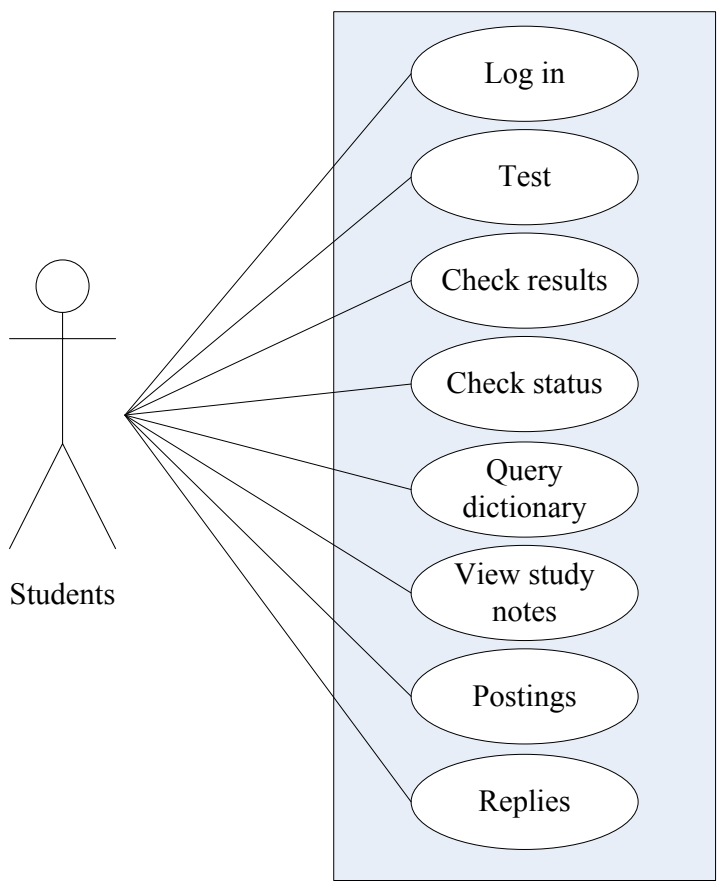

Fig. 2. The use case of student

Table 1. The main function of the system

\begin{tabular}{ll}
\hline Main function & Description \\
\hline Information Manage- & Information management functions include rights management, including \\
ment Function & personal information maintenance, query, delete, modify \\
Learning management & Teachers supervise and manage the learning process of students \\
functions & Students participate in online testing of the system and check their own test \\
Online test function & scores \\
Interaction function & Teachers answer students' questions, post or replies \\
\hline
\end{tabular}

\subsection{System Non-functional Requirements and Operating Environment}

Non-functional Requirements. Scalability, security, objectivity, real-time, maintainability and flexibility are the major non-functional requirements of the system. Scalability is the need for a system to expand the business function in order to meet the new needs of the user, which can extend the life of the system. Security is to protect the system users' personal information and restrict users' authority, so as to ensure the safety of the system, teaching test scores, etc. Manageability is that the system can adjust teaching programs and reset learning tasks according to student feedback and test scores. Real-time refers to that the system respond to the user's response in time, including score query, grading standard modification, posting and reply, etc. Maintainability refers to the system's high code readability and the appropriate docu- 
ment is saved at each stage of the system development. Fexibility refers to that the user can enter the relevant information, and easily manage and visit the database.

System Operating Environment. Computer hardware: CPU Intel i7 920 processor, memory Kingstone DDR3, graphics card GeForce GT640 2G DDR5, Samsung S27A550H display, integrated network card; operation system: Windows7 ultimate; install software: DDR5, Hun, 1.4.

\section{Design of Online English Learning System}

The system design mainly includes the system architecture, the network architecture and the system overall function module, as well as the database table.

\subsection{System Architecture and Network Architecture Design}

The architecture of the system takes the Tomcat server as the core, accepts the HTTP request from the browser client, then processes the MySQL database, and finally returns the results to the client.

The design of the system architecture of college English online learning system is shown in Figure 3.

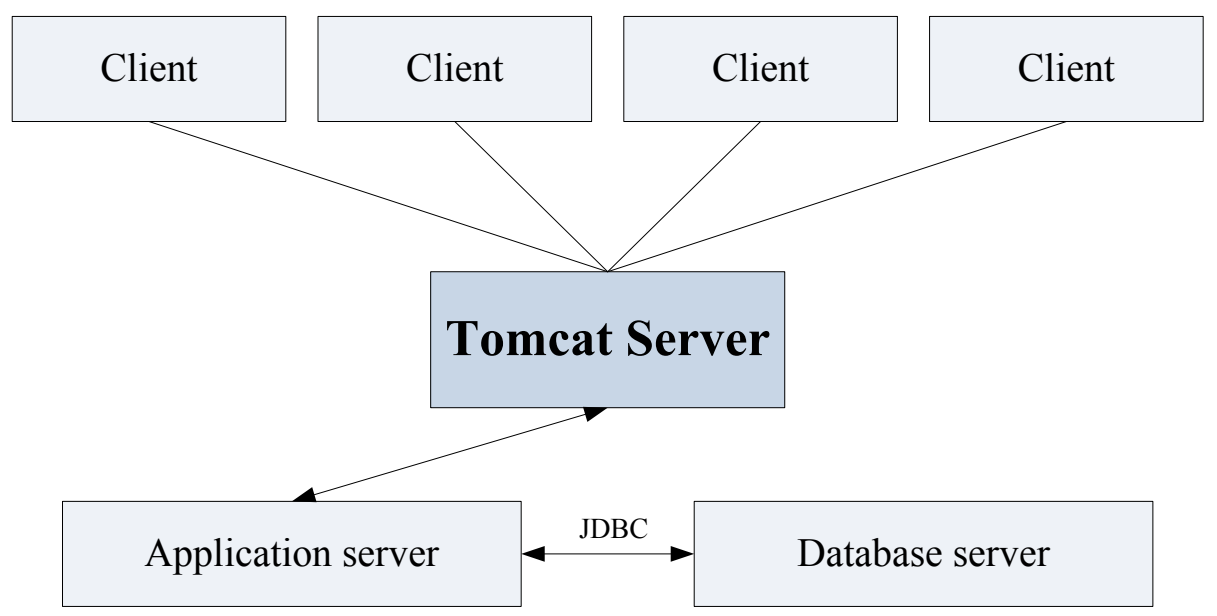

Fig. 3. The system structure

The network architecture of the system is designed as follows: the server is connected to each switch, and is connected to the campus network through a hardware firewall and a router; on the other hand, each switch is connected to computers in the computer lab, the teaching building and the student dormitory, which forms the basic network architecture. The system is mainly used for small-scale internal network, so the system implementation speed and efficiency are guaranteed with small load and high security. 
The overall function modules of the system are divided into three, namely the administrator module, teacher module, and student module. The corresponding system functions is designed and analyzed according to the system user needs, as shown in Figure 4.

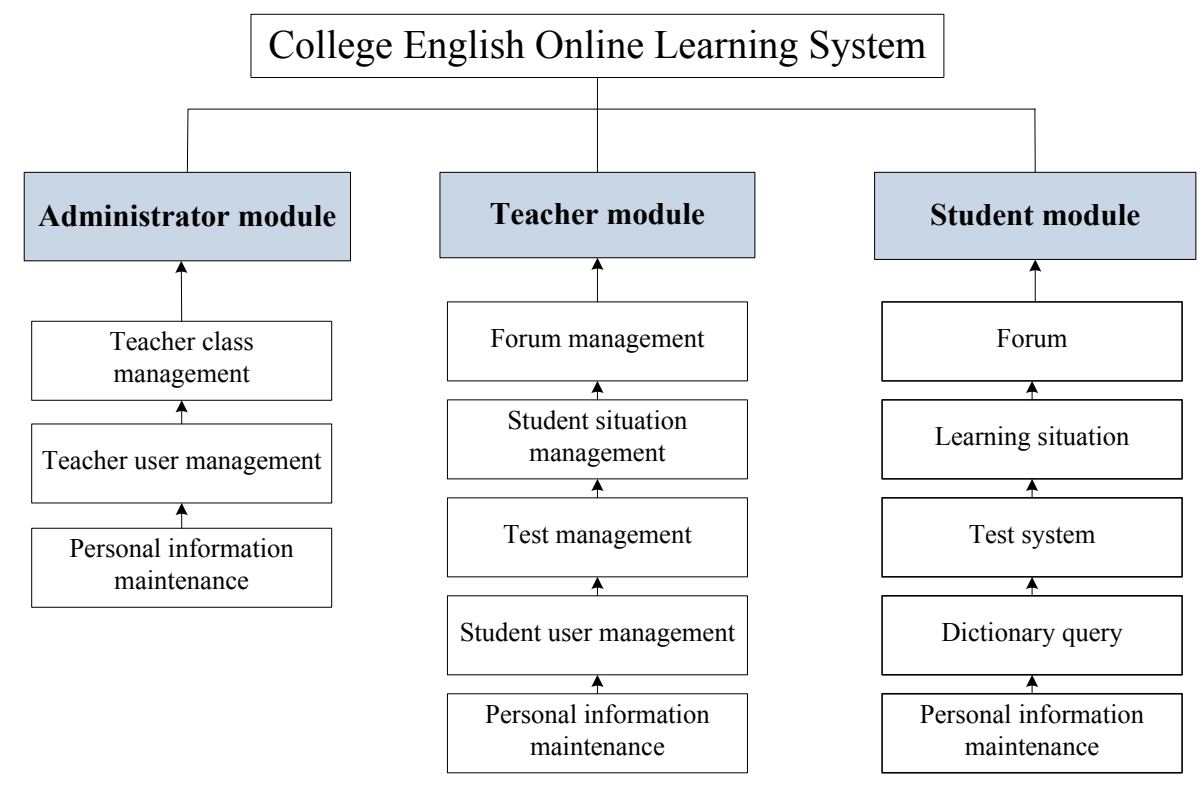

Fig. 4. Overall function module

\subsection{Database Design}

The conceptual design of the database refers to analysis of the collected information and data, and determination of the entities, attributes and connections, namely a concept model of the database designed by the entity-relationship method. Design the fields, field types, field length and other related attributes of the database table for the database storing. As shown in Table 2, it is the data table of the system administrator that records administrator related information, and the other roles in the system are similar to the format in the table.

Comprehensive test forms, comprehensive test coupon tables, test control tables, comprehensive test answer management tables, writing problem tables, writing test forms, student notebook forms, learning schedule and timeline, posting and replying data tables are similarly stored as Table 2. All user information and teaching management information connect with the system through JDBC after storing in the MySQL database. 
Table 2. The table of Administrator

\begin{tabular}{rllcll}
\hline No. & Field names & Field Type & Empty or not & key & Field description \\
\hline $\mathbf{1}$ & Ad_loginName & Varchar & $\mathrm{N}$ & Home key & Log name \\
$\mathbf{2}$ & Password & Varchar & $\mathrm{N}$ & & Password \\
$\mathbf{3}$ & RealName & Varchar & $\mathrm{Y}$ & & Real name \\
$\mathbf{4}$ & Dep_NO & Varchar & $\mathrm{N}$ & foreign key & department \\
$\mathbf{5}$ & Phone & Varchar & $\mathrm{Y}$ & & Contact number \\
$\mathbf{6}$ & E_Mail & Varchar & $\mathrm{Y}$ & & email \\
$\mathbf{7}$ & QQ & Varchar & $\mathrm{Y}$ & & QQ \\
$\mathbf{8}$ & Demo & Memo & $\mathrm{Y}$ & & remark \\
\hline
\end{tabular}

\subsection{System Interface Design and Implementation}

The system user can obtain the system login permission after completing the system registration. The system interface includes a login interface, an administrator interface, a teacher management interface and a student activity interface.

As shown in Figure 5, in the teacher management interface, the teacher can delete or modify the student information and master students learning conditions.

\begin{tabular}{|c|c|c|c|c|c|}
\hline$\leftrightarrow \oplus \mathrm{P}_{\mathrm{p}: / / \text { localhost/cam }}$ & . c e & $x$ & & & $n+\infty$ \\
\hline$\Leftrightarrow$ & & 會一 & 回 的 一页面 & $(P)$ 一安全 $(S)$ 工具 $(\mathrm{C}$ & - 8 - \\
\hline Colle & English & line Le & annings S & ystem & quit \\
\hline Home page $\mathrm{O}$ Adr & tor module & her module & Student modu & & \\
\hline Student I nform & agsant & & & & \\
\hline Please enter the stu & ame: & Query & Reset & & \\
\hline User code & Name & Class & Delete or not & Modify or not & \\
\hline 20100000 & Zhanghua & 1 & Delete & Modify & \\
\hline 20100001 & Qinguan & 3 & Delete & Modify & \\
\hline 20100002 & Zhangliang & 2 & Delete & Modify & \\
\hline 20100003 & Liujie & 4 & Delete & Modify & \\
\hline 20100004 & Niujia & 1 & Delete & Modify & \\
\hline
\end{tabular}

Fig. 5. Teacher Management Interface

As shown in Figure 6, the system is an English online learning platform to meet the exchanges between students and teachers, on which students can post questions according to their own doubts, and teachers reply appropriately to the students' posts. This platform effectively meets the teacher-student exchange in English learning. 


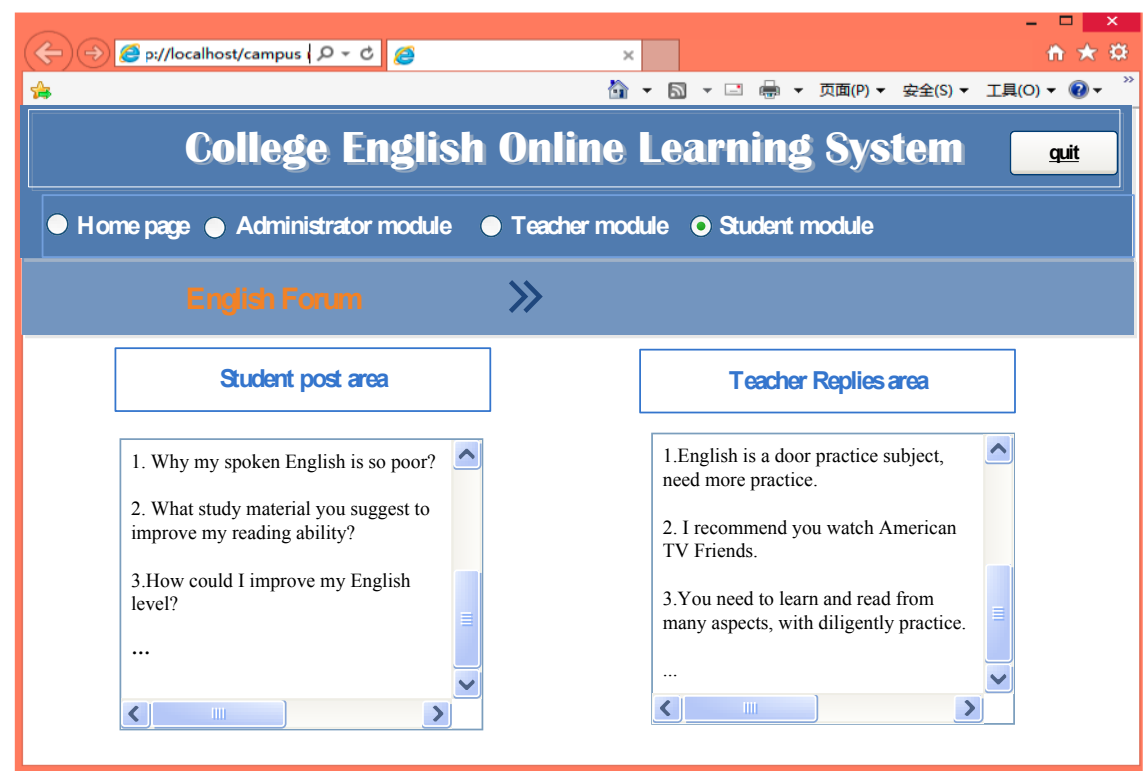

Fig. 6. Student forum interface

The interfaces of other systems are not described here one by one. The system can run stably in the local campus network, and the data access and transmission meet the expected requirements. Administrators, students and teachers can participate well in the online English learning system, so as to improve English teaching efficiency and effectiveness.

\section{Conclusion}

Aiming at the problems of incomplete function and unstable operations of existing English learning systems, this paper designed an online English learning system based on $\mathrm{B} / \mathrm{S}$ for college students. First, the user needs and functional requirements for the system were analyzed in detail, with the appropriate computer technology selected and the network architecture and function modules designed. Finally, the relevant interfaces were displayed after the design was completed. The main creation and innovations of this paper are as follows:

1. With B/S as software architecture, MySQL as database development tool and JSP as the programming technology, the online English learning system for college students was designed, which satisfied users' functional and non-functional needs.

2. Combining computer and Internet technology, English learning has been networked and information-based, which will help to improve the quality of English teaching in colleges and universities.

3. The system's security, extensibility, flexibility and other features will facilitate the second development of the system to meet the user's new functional requirements. 


\section{References}

[1] Luo, J., Jie, Y. (2011). Problems and countermeasures of educational informationization construction in colleges and universities. Human Immunology, 63(10), 496-500. https://doi.org/10.1007/978-3-642-23321-0 77

[2] Bernhardsdóttir, A. E., Thorvaldsdóttir, S., Sigbjörnsson, R., Musacchio, G., Nave, R., Falsaperla, S. (2012). Disaster prevention strategies, based on an education information system. Review of Scientific Instruments, 53(1), 1-11.

[3] Roca, J. C., Chiu, C. M., Martínez, F. J. (2006). Understanding e-learning continuance intention: an extension of the technology acceptance model. international journal of humancomputer studies, 64(8), 683-696. International Journal of Human-Computer Studies, 64(8), 683-696. https://doi.org/10.1016/j.ijhcs.2006.01.003

[4] Aldujaily, A. (2008). Personality effect in the design of adaptive e-learning systems: a thesis presented in partial fulfilment of the requirements for the degree of doctor of philosophy in information system at massey university. Journal of Molecular Biology, 342(2), 571-83.

[5] Klašnja-Milićević, A., Ivanović, M., Nanopoulos, A. (2015). Recommender systems in elearning environments: a survey of the state-of-the-art and possible extensions. Artificial Intelligence Review, 44(4), 571-604. https://doi.org/10.1007/s10462-015-9440-Z

[6] Zhang, D., Zhao, J. L., Zhou, L., Nunamaker, J. F. (2015). Can e-learning replace classroom learning?. Communications of the Acm, 47(5), 75-79. https://doi.org/10.1145/98 6213.986216

[7] Ahn, K., Kim, S., Hong, K., Han, K. J. (1999). Design and implementation of browser/server environment-based hospital information search system (bs-hiss). IEEE, 2, 15691572 vol.2. https://doi.org/10.1109/TENCON.1999.818737

[8] Vertrees, J., Barritt, P., Whitten, S., Hilser, V. J. (2005). Corex/best server: a web browserbased program that calculates regional stability variations within protein structures. Bioinformatics, 21(15), 3318-3319. https://doi.org/10.1093/bioinformatics/bti520

[9] Mateosian, R. (2003). Javaserver pages developer's handbook [book review]. IEEE Micro, 23(5), 79-80. https://doi.org/10.1109/MM.2003.1240205

[10] Hibbard, W., Rueden, C., Emmerson, S., Rink, T., Glowacki, D., Whittaker, T., et al. (2005). Java distributed components for numerical visualization in visad. Communications of the Acm, 48(3), 98-104. https://doi.org/10.1145/1047671.1047676

[11] Giacomo, M. D. (2005). Mysql: lessons learned on a digital library. IEEE Software, 22(3), 10-13. https://doi.org/10.1109/MS.2005.71

[12] Linksvayer, T., Mikheyev, A. (2015). Data tables from mysql database for gene expression analysis. Development, 130(25), 6221-31.

[13] Haryo, S. S. (2013). Pembuatan aplikasi e-commerce daging se'i dengan menggunakan php dan mysql. Gene Therapy, 8(4), 308-15.

[14] Sun, P. C., Cheng, H. K., Finger, G. (2010). Critical functionalities of a successful elearning system - an analysis from instructors' cognitive structure toward system usage. Decision Support Systems, 48(1), 293-302. https://doi.org/10.1016/j.dss.2009.08.007

[15] Enke, J., Tisch, M., Metternich, J. (2016). Learning factory requirements analysis - requirements of learning factory stakeholders on learning factories. Procedia Cirp, 55, 224229. https://doi.org/10.1016/j.procir.2016.07.026

[16] Zhao, Z., Feng, S., Zeng, Q., Fan, J. (2010). Personalized knowledge acquisition through interactive data analysis in e-learning system. Journal of Computers, 5(5). 


\section{$7 \quad$ Authors}

Lidan Mao received the B.A. degree in English Major from JiLin University, China, in 2005, and the Master of Arts degree from the Foreign Language College, Agriculture University of Hebei, China, in 2012. Now she is a lecturer in Foreign Language College, Agriculture University of Hebei, Baoding 071001, China.

Jun Miao received the B.A. degree in English Major from North China University of Science and Techology in 2005. Now she is a lecturer in Foreign Language College, Agriculture University of Hebei, Baoding 071001, China.

Article submitted 07 February 2018. Final acceptance 23 February 2018. Final version published as submitted by the author. 